\title{
O STATUS EPISTEMOLÓGICO DA CONCEPÇÃO TELEOLÓGICA DO MUNDO NA IDEIA DE UMA HISTÓRIA UNIVERSAL DE UM PONTO DE VISTA COSMOPOLITA DE KANT
}

\author{
Ricardo Machado Santos*
}

\begin{abstract}
Resumo: O objetivo deste trabalho é discutir o texto Ideia de uma História Universal de um ponto de vista cosmopolita de Kant, argumentando a favor de que a concepção de progresso histórico presente nesta obra seja entendida como uma ideia regulativa, servindo para orientar a atividade humana, isto é, defender-se-á que podemos conceber, já neste texto, sem incorrer num uso dialético da razão, uma teleologia que nos permita vislumbrar um horizonte para a execução de princípios práticos. Palavras-chave: teleologia, princípios regulativos, história.
\end{abstract}

Abstract: The aim of this paper is to discuss the text Idea for a Universal History from a cosmopolitan point of view of Kant, arguing that the conception of historical progress in this present work is understood as a regulative idea, serving to guide human activity, that is, it will be argued that we can conceive, already in this work, without incurring a dialectical use of reason, a teleology that allows us to envision a horizon for the implementation of practical principles.

Keywords: teleology, regulative principle, history.

\footnotetext{
* Mestrando em Filosofia do Instituto de Filosofia e Ciências Humanas UNICAMP.
} 
|112|

O Status Epistemológico da concepção teleológica do mundo...

\section{Introdução}

No texto Idéia de uma história universal de um ponto de vista cosmopolita ${ }^{1}$, Kant adota uma concepção teleológica da natureza, isto é, a concepção segundo a qual ela "atua" segundo fins. A adoção de tal perspectiva por parte do filósofo, neste texto de 1784 , tem sido um dos pontos mais problemáticos e mais discutidos no que diz respeito ao seu pensamento sobre a história.

Há uma extensa bibliografia sobre essa questão, vale dizer, a questão do "status epistemológico" de sua filosofia da história, do "lugar sistemático da filosofia da história de Kant no todo do seu projeto crítico-transcendental" (Hamm, 2005, p. 67). Estava Kant em condições de elaborar uma teleologia regulativa no início da década de 80 ou tal só foi possível no seu pensamento mais maduro, especialmente com o lançamento da KU? Estaria o próprio Kant caindo num uso dialético da ideia transcendental teológica, ao atribuir a esta natureza/providência determinadas propriedades, como por exemplo, uma vontade e uma causalidade em relação ao mundo sensível, quando poderíamos apenas admitir semelhante ideia de forma problemática, como não impossível de ser pensada? Como podemos pensar, de forma não dogmática, uma concepção de história que se baseia na noção de um propósito e de um plano oculto da natureza? E ainda tal teleologia é elaborada num propósito especulativo ou prático?

Nas várias respostas dadas pelos comentadores, vemos que estes tomam posições bastante matizadas: Yovel (Cf. 1980, p. 154-157), por exemplo, acredita ser este um "deslize" metafísico de Kant; autores como Beck (Cf. 1988, p. 413-414) e Mulholland (Cf.1987, p. 39) acreditam, cada um a seu modo, que tal concepção não contradiz a $\mathrm{KrV}$ e tem um propósito especulativo; Lebrun

\footnotetext{
${ }^{1}$ A partir daqui serão utilizadas, de acordo com os títulos originais em alemão, as seguintes abreviaturas das obras de Kant: IaG - Idéia de uma história universal de um ponto de vista cosmopolita; KU - Crítica da faculdade de julgar; $\mathrm{KrV}$ - Crítica da razão pura; RGV - A religião dentro dos limites da simples razão; SF - O Conflito das faculdades; Prol - Prolegômenos a toda metafísica futura.
} 
(Cf. 1986, p. 92) a apresenta como algo equivalente a um postulado da razão prática; Lindestedt (Cf. 1999, p. 129-147) vai mais além e afirma que a ideia de um progresso histórico é efetivamente um postulado da razão; Guyer (Cf. 2000, p. 425-433) sugere que a concepção de história de Kant deva ser pensada mais como um ideal regulativo da razão e não como um postulado.

Discutiremos, então, baseados nos textos de Kant e levando em conta alguns argumentos levantados pelos comentadores acima, a possibilidade de se atribuir propósitos à natureza e de se pensar a história como uma teoria para a justificação ou garantia de determinados fins políticos e morais, e desta forma estabelecer o status sistemático ou epistemológico da concepção de história presente na IaG.

Contudo, em primeiro lugar, temos de circunscrever o alcance de nossa investigação: o que se tem aqui em vista é uma tentativa de pensar a teleologia tal como exposta na IaG no horizonte da filosofia crítica. É até certo ponto evidente que a possibilidade de uma teleologia (e, portanto sua filosofia da história) na filosofia kantiana ganha outra luz a partir do lançamento da KU; da mesma forma sabemos que a ideia de progresso e mesmo a relação entre moralidade e história pode ser pensada de forma distinta da IaG, sobretudo em alguns textos da década de 90 (como por exemplo a RGV e o SF). Tentaremos, pois, investigar a possibilidade de pensarmos criticamente a concepção de história exposta na IaG, apoiados nos textos do início da década de 80 .

\section{1 - O Status Epistemológico da concepção de história da IaG}

Yovel, como já dissemos anteriormente, defende haver no pensamento de Kant uma linha evolutiva; neste sentido ele intitula um dos tópicos do seu trabalho como "Da teleologia dogmática à crítica", entendendo que essa teleologia dogmática encontra-se na $\mathrm{IaG}$, pois neste texto Kant 
$|114|$

O Status Epistemológico da concepção teleológica do mundo...

[...] parece cometer o maior erro dogmático. Ele atribui a natureza como tal um plano teleológico oculto, pelo qual a totalidade da história empírica é explicada e predita; mas isto permanece em aberto conflito com a Crítica da Razão Pura, a qual admite apenas princípios mecânicos na natureza. De acordo com a Crítica, nossa lógica sintética, a qual constitui a estrutura ontológica das entidades naturais, inclui apenas a categoria de causalidade, excluindo a categoria de propósito. Usando esta categoria em explicações cognitivas, transgride-se os limites da razão e se cai em uma transcendente especulação. Parece, em consequência, que a Idéia [IaG] comete o erro que a Crítica proíbe. (Yovel, 1980, p. 154-155). ${ }^{2}$

Tendo em vista tal posição de Yovel, cumpre inicialmente analisar o seguinte ponto: na $\mathrm{KrV}$, de fato, Kant admite unicamente princípios mecânicos em relação à natureza? Ou podemos pensar de alguma forma, em consonância com a primeira Crítica, a natureza teleologicamente? Se realmente Yovel estiver correto suas conclusões de que a IaG "pertence ainda ao pensamento pré-crítico de Kant" e de que neste texto encontramos "vestígios de seu pensamento dogmático" estarão corretas.

Se levássemos em conta apenas o que Kant expõe na Analítica transcendental, onde de fato defende-se que a natureza tem de ser pensada somente mecanicamente, Yovel estaria coberto de razão.

2 "The Idea [IaG] seems to commit a major dogmatic error. It ascribe to nature as such a hidden teleological plan, by which the totality of empirical history is to be explained and predicted; but this stands in open conflict with the Critique of Pure Reason, which admits only of mechanistic principles in nature. According to the Critique, our synthetic logic, which constitutes the ontological structure of natural entities, includes only the category of causality, excluding the category of purpose. Using this category in cognitive explanations transgresses the boundaries of critical reason and lapses in to transcendent speculation. It seems, therefore, that the Idea commits precisely the error that the Critique forbids." 
Contudo, no Apêndice à Dialética Transcendental ${ }^{3}$, Kant apresenta uma posição diferente.

Durante toda Dialética Transcendental Kant procura confirmar a sua posição segundo a qual todo o conhecimento deve limitar-se ao âmbito da experiência possível. Vale dizer, só podemos conhecer dos objetos aquilo que é dado numa experiência possível, dado que as intuições puras da sensibilidade e os conceitos puros do entendimento não têm, nem podem ter, segundo Kant, outro uso senão o de tornar possível a experiência. E malgrado não podermos considerar nossa experiência como o único modo possível de conhecimento, isto é, que as nossas intuições puras sejam as únicas possíveis, fora dos limites da experiência não podemos dar nenhum conceito definido das coisas. Dito de outro modo, só conhecemos o fenômeno, as coisas como são em si permanecem com caráter meramente problemático.

Contudo, assinala Kant, não conseguimos nunca deixar de procurar esta realidade numênica. Isto porque a razão busca a totalidade das condições, e unicamente o incondicionado torna possível essa totalidade do condicionado (Kant, 1980, p. 190/ B 379) ${ }^{4}$.

A nossa curiosidade acerca do transcendente direciona-se basicamente a três espécies de questões: a psicológica; as cosmológicas; e a questão teológica. Que correspondem às três ideias transcendentais:

Ora, todos os conceitos puros em geral têm a ver com a unidade sintética e os conceitos da razão pura (ideias transcendentais), por sua vez, com a unidade incondicionada de todas as condições em geral. Consequentemente, todas as ideias transcendentais podem reduzir-se a três classes, cuja primeira contém

\footnotetext{
${ }^{3}$ Doravante Apêndice.

${ }^{4}$ A Edição B corresponde à segunda edição original da $\mathrm{KrV}$ de 1787 , o número em seguida corresponde à sua paginação original. Da mesma forma, nas demais obras de Kant citadas aqui, "A" ou "B" representará respectivamente a primeira ou a segunda edição original da obra.
} 
$|116|$

O Status Epistemológico da concepção teleológica do mundo...

a unidade absoluta (incondicionada) do sujeito pensante, a segunda, a unidade absoluta da série das condições do fenômeno, a terceira, a unidade absoluta da condição de todos os objetos do pensamento em geral. (Kant, 1980, p. 195/ B 390).

Neste sentido, mostra Kant que, não obstante tendermos a especular sobre estas três ideias, pois só assim a razão encontra satisfação, nunca podemos ter um conceito determinado do objeto das mesmas, pois são meros entes de entendimento e desta forma: a) se os pensarmos por meio de simples conceitos, estes não fariam nenhum sentido, seriam vazios, pois não se refeririam a nada de determinado; e b) se por outro lado os pensarmos por meio de propriedades derivadas do mundo sensível, eles deixariam de ser entes de entendimento e passariam a ser pensados como objetos fenomênicos, o que seria absurdo. Portanto todas as tentativas até então feitas pela metafísica são dialéticas, transcendentes. E é justamente uma crítica aos erros e ilusões até então cometidos pela razão, ao tentar especular sobre essas ideias transcendentais, que Kant procura fazer na Dialética.

Já no Apêndice, Kant procura mostrar que as ideias transcendentais podem ter um uso imanente à experiência, ou seja, embora as ideias transcendentais possam ter um uso transcendente (que é combatido por Kant amplamente na Dialética Transcendental) devemos supor que assim como as categorias "dirigem todo o uso do entendimento na experiência", as ideias transcendentais devem determinar "segundo princípios o uso do entendimento na totalidade da experiência" (p. 190/ B 378). Pois tais ideias "[...] não são inventadas arbitrariamente, mas propostas pela natureza da razão mesma, relacionando-se por isso ao uso total do entendimento" (p. 192/ B 384).

Neste sentido, argumenta Kant

Tudo o que se funda na natureza das nossas forças tem que ser adequado a um fim e concordar com o correto uso dessas forças [...]. Portanto, tudo faz crer 
que as ideias transcendentais tenham a sua utilidade e, por conseguinte um uso imanente, se bem que possa ter uma aplicação transcendente e também por isso ser enganosas quando a sua significação é ignorada e elas são tomados por conceitos das coisas reais. (Kant, 1980, p. 319/ B 670-671).

Isto é, Kant parte do pressuposto segundo o qual, não podemos considerar as ideias transcendentais em si como transcendentes, pois uma vez que elas são dadas pela natureza da nossa razão, e sendo absurdo supor que este tribunal supremo que é a razão contenha erros e ilusões originários, não são as ideias, mas o seu uso que deve ser considerado transcendente ou imanente.

Qual, no entanto, seria este uso imanente das ideias da razão? Como o entendimento por si só não é capaz de dar uma unidade sistemática aos seus conhecimentos, e como a razão não se reporta diretamente aos objetos, Kant procurará defender que o uso imanente da razão em relação à experiência é o de orientar o entendimento conferindo a maior unidade possível dos seus conhecimentos. A função da razão seria a de proporcionar uma unidade por meio da qual se possa dar a máxima unidade e a máxima extensão ao sistema dos conhecimentos do entendimento.

Para isso, além da ideias transcendentais, a razão dispõe da ideia de uma unidade sistemática, pela qual concebemos os conhecimentos do entendimento como um todo sistemático:

Se temos presentes os conhecimentos do nosso entendimento em todo o seu âmbito, então descobrimos que aquilo de que a razão dispõe de modo totalmente peculiar, e que procura realizar, é o sistemático do conhecimento, isto é, sua interconexão a partir de um princípio. Esta unidade da razão pressupõe sempre uma ideia, a saber, da forma de um todo do conhecimento que precede o conhecimento determinado das partes e contém as condições para determinar a priori o lugar de cada parte e a sua relação 
$|118|$

O Status Epistemológico da concepção teleológica do mundo...

com as demais. Tal ideia postula por isso uma unidade completa do conhecimento do entendimento; graças a essa unidade, o conhecimento não se torna simplesmente um agregado contingente, mas um sistema interconectado segundo leis necessárias. (Kant, 1980, p. 320/ B 673).

Ou seja, a razão busca por meio da ideia de uma unidade sistemática, conceber os conhecimentos do entendimento como um todo ordenado e não apenas como simples agregado contingente. Este todo ordenado deve ser pensado como anterior às partes de modo que se possa melhor compreender tais partes, não as pensando apenas como conhecimentos isolados, mas como partes de um todo, isto é, como estando em conexão com um sistema do conhecimento.

Cabe agora compreendermos como se relacionam neste processo as ideias transcendentais com a ideia de uma unidade sistemática. Certamente as três ideias transcendentais não podem ser representadas como princípios constitutivos de ampliação do nosso conhecimento, mas antes apenas como "princípios regulativos da unidade sistemática do múltiplo do conhecimento empírico em geral, que deste modo é mais consolidado e retificado do que aconteceria, sem tais ideias, mediante o simples uso dos princípios do entendimento" (Kant, 1980, p. 331/ B 700).

Ademais, tais ideias, como todas as outras ideias, não têm nem podem ter um objeto que se lhes corresponda na experiência, contudo, afirma Kant, elas podem servir como um analogon a um esquema da sensibilidade, de modo a conduzir todas as regras empíricas à unidade sistemática e ampliar deste modo o conhecimento da experiência. Vale dizer, sem esquemas da sensibilidade as ações do entendimento tornam-se indeterminadas; todavia, mesmo não se podendo buscar na sensibilidade um esquema para a total unidade sistemática, há que ser buscado algo análogo a tal esquema (Kant, 1980: p. 329/ B 693), e tais são as ideias transcendentais. 


\title{
Kant nos dá um exemplo ilustrativo:
}

\begin{abstract}
Assim digo que o conceito de uma inteligência suprema é uma simples ideia, isto é, que a sua realidade objetiva não deve consistir no fato dele precisamente se referir a um objeto (pois com esta significação não poderíamos justificar a sua validade objetiva), mas que é só um esquema ordenado segundo as condições da máxima unidade da razão e relativo ao conceito de uma coisa em geral, servindo somente para manter a máxima unidade sistemática no uso empírico da nossa razão na medida em que o objeto da nossa razão é por assim dizer derivado do objeto fictício dessa ideia enquanto seu fundamento ou sua causa. Em tal caso, diz-se por exemplo, que as coisas do mundo têm que ser consideradas como se obtivessem sua existência de uma inteligência suprema. Deste modo, a ideia é propriamente só um conceito heurístico e não um conceito ostensivo e indica não como um objeto é constituído, mas como sob sua direção nós devemos procurar a sua constituição e a conexão dos objetos da experiência em geral. (Kant, 1980, p. 331/ B 698- 699).
\end{abstract}

Destarte, os entes aos quais as ideias trancendentais se referem, não são admitidos em si mesmos; sua realidade é admitida tão somente como esquemas do princípio regulativo da unidade sistemática de todo conhecimento, servindo apenas como análogos a coisas reais e não efetivamente como coisas reais, isto é, não como coisas em si mesmas.

É a partir disto que Kant considera legítima a perspectiva pela qual se considera o mundo teleologicamente, pois

A mais alta unidade formal, que repousa unicamente sobre conceitos da razão é a unidade das coisas conforme a um fim; e o interesse especulativo da razão torna necessário encarar toda ordem do mundo como se brotasse da intenção de uma razão mais 
$|120|$

O Status Epistemológico da concepção teleológica do mundo...

elevada que todas. Um tal princípio abre perspectivas totalmente novas a nossa razão aplicada ao campo da experiência, ou seja, de conectar as coisas do mundo segundo leis teleológicas e deste modo alcançar a sua máxima unidade sistemática. (Kant, 1980, p. 338/ B 714-715).

Kant, portanto não hesita em considerar, ainda que como um princípio heurístico, regulador, o mundo como produto de uma "sábia intenção", e fala até de uma "sabedoria e providência da natureza" (p. 344/ B 729).

Esse exame, ainda que pouco detalhado, mostra que ao contrário do que defende Yovel, Kant admite sim na KrV, uma concepção de natureza ademais da meramente mecânica da Analítica. E parece difícil também, dado o esforço e rigor de Kant em fundamentar um tal uso das ideias transcendentais (lembremos que ele tinha como objetivo mostrar que a razão não contém erros e ilusões originários e portanto que ela contemple também um uso imanente à experiência para tais ideias além de tornar possível a realidade da idéia de unidade sistemática dos conhecimentos do entendimento), defender que isso seja meramente um deslize pré-crítico ou metafísico.

Podemos, no entanto nos perguntar se unicamente a partir do que Kant expõe no Apêndice podemos fundamentar a IaG, ou melhor se esta pode ser deduzida daquele. Há que se notar que, no Apêndice, nosso filósofo acentua várias vezes que a admissão daquela perspectiva teleológica se dá apenas com um propósito teórico-especulativo.

Semelhante interpretação assume Mulholland que entende que na IaG Kant se propõe um "especulativo estudo da história que justifica nossa esperança de que as inclinações naturais dos seres humanos compelirão os indivíduos a produzir repúblicas" (1987, p. 39) e também Beck (tal como nos descreve Lindsdedt) que defende que as noções encontradas na IaG "funcionam como conceitos regulativos para o aperfeiçoamento da razão especulativa em geral e, especificamente, para o melhoramento do estudo da 
história" de modo que no texto de 1784, Kant estabelece "conceitos sobre a progressão teleológica da história pelos quais se permite melhor compreender eventos empíricos pela colocação deles em uma correta estrutura para o acabamento de um completo sistema do pensamento" (Lindstedt, 1999, p. 134).

\section{2 - A IaG pensada com um propósito prático}

Tais concepções são bem plausíveis, sobretudo considerando o que vimos no Apêndice. Não obstante, entre a KrV (1781) e a IaG (1784) encontram-se os Prol (1783).

Nos Prol, mais precisamente na Conclusão da determinação dos limites da razão pura, Kant, assim como no Apêndice, procura mostrar como seria possível uma utilização das ideias transcendentais sem que se caia no erro e na ilusão. E, da mesma forma que no referido tópico da $\mathrm{KrV}$, Kant assinala que embora diante das especulações sobre as realidades transcendentes nunca alcancemos um conhecimento seguro, não conseguimos nunca deixar de especular sobre elas, pois "a experiência nunca satisfaz totalmente a razão" (Kant, 1986a, p. 147/ A 169), ademais existe no homem como que uma disposição natural para conceitos transcendentes e juízos metafísicos (p. 158/ A 183- 184). Assim, o filósofo procura indicar qual é e como pode se dar um uso adequado de semelhante disposição.

Kant propõe então, que não tentemos conhecer as propriedades da ideia de sujeito, de mundo, ou de um ser supremo tomados em si mesmos, mesmo porque são meras ideias e, portanto não possuem correlatos na experiência, mas antes que pensemos tão somente a relação de tais entes com o mundo dos sentidos, conectando-os pela razão (p. 152/ A 175). Para explicar melhor como isto se daria ele propõe que pensemos, a título de exemplo, o conceito de um ente supremo, ou seja, a ideia teológica. Este ponto será de fundamental importância para a nossa investigação, pois entendo que pensando tal relação (de um ente supremo com o mundo sensível, e sem atribuir ao primeiro nada em si mesmo) é que podemos pensar uma natureza teleológica 
$|122|$

O Status Epistemológico da concepção teleológica do mundo...

com determinados propósitos em relação ao gênero humano, e isto com uma finalidade prática.

Pois bem, Kant opõe um conceito deísta a um teísta de ente supremo; o primeiro seria um conceito puro da razão "o qual representa apenas uma coisa que contém toda a realidade, sem poder determinar nenhuma delas" (p. 151/ A 175). O segundo (o conceito teísta), pelo contrário, é uma determinação mais precisa deste conceito, portanto, com qualidades empíricas, isto é, o conceito representa um conceito antropomórfico de divindade, o que implica que ele vai além do permitido por uma razão crítica, visto que, entendido dessa forma, tal conceito visa atribuir qualidades positivas (empíricas) ao que só podemos conhecer negativamente.

Todavia, segundo Kant, podemos admitir uma espécie particular de antropomorfismo: se confinarmos nosso juízo relativamente à relação que pode ter um ente supremo com o mundo sensível, permanecemos dentro dos limites do nosso conhecimento; pois não lhe atribuímos nenhuma qualidade em si mesmo, mas somente à sua relação com o mundo, sem no entanto cair em um antropomorfismo dogmático, mas simbólico "que de fato só diz respeito à linguagem e não ao próprio objeto" (p. 152/ A 175). Na sequência, diz Kant:

Quando digo: somos obrigados a ver o mundo como se ele fosse a obra de um entendimento e de uma vontade suprema, não digo na realidade mais do que: assim como um relógio, um navio, um regimento, se referem ao relojoeiro, ao construtor ao comandante, assim o mundo sensível (ou tudo que constitui o fundamento deste complexo de fenômenos) refere-se ao desconhecido, que através disso conheço não pelo que é em si mesmo, mas o que é para mim, a saber, em relação ao mundo, do qual sou parte. (Kant, 1986a, p. 152/ A 175).

O que ele quer dizer é que considerar o mundo de tal forma, possuindo tal relação com um ente supremo, se por um lado não 
diz nada sobre semelhante ente em si, por outro nos permite pensar o mundo segundo um fim; do mesmo modo que um navio é feito por seu construtor com o fim de navegar (o que me possibilita ter uma melhor compreensão das partes com o todo), eu posso pensar o mundo como feito com determinados fins racionais.

\title{
No § 58 Kant acrescenta:
}

\begin{abstract}
Um conhecimento desta espécie o é por analogia, que não é, como comumente se entende, uma semelhança imperfeita entre duas coisas, mas significa uma semelhança perfeita de duas relações entre duas coisas completamente dessemelhantes. Por meio desta analogia resta-nos um conceito do ente supremo suficientemente determinado para nós, embora tenhamos que deixar de lado tudo que poderia determiná-lo absolutamente em si mesmo; pois nós o determinamos relativamente ao mundo e a nós, e não necessitamos mais do que isto. (Kant, 1986a, p. 152/ A 176).
\end{abstract}

Em suma, uma pressuposição de tal relação de um ente supremo com o mundo, isto é, o conhecimento simbólico analógico da divindade é, para Kant, uma "metafísica segundo a sua possibilidade subjetiva" (p. 158/ A 183), ou seja, na medida em que é usada pelo sujeito, não para pensar Deus, mas por meio dele pensar o mundo, para que se possa ter um maior uso de nossa razão.

É neste sentido que Kant dirá ter encontrado uma finalidade adequada àquela nossa disposição natural para a metafísica, vale dizer, se o uso das ideias transcendentais não nos permite uma ampliação do nosso conhecimento especulativo, pelo menos servem para "dar às idéias morais, espaço fora do campo da especulação" (p. 160/ A 186). Ou seja, esta metafísica subjetiva, 
|124|

O Status Epistemológico da concepção teleológica do mundo...

tem por objeto o conhecimento prático, e não só o especulativo, como sugere o Apêndice à Dialética Trancendental.

Em síntese, esta metafísica subjetiva visa, portanto, dar um campo maior para "[...] princípios práticos que, sem encontrar diante de si um tal espaço para a sua necessária expectativa e esperança, não podem se estender à universalidade, da qual a razão necessita para o seu fim moral." (p. 159/ A 184- 185).

Destarte, isto é, tendo Kant nos Prol mostrado a possibilidade de uma teleologia com um caráter claramente regulativo, voltada para o campo prático, ou seja, uma teleologia que nos permita pensar não apenas uma unidade sistemática em vista da qual possamos fazer um maior uso empírico de nossa razão, como Kant propõe no Apêndice, mas uma teleologia que nos permita vislumbrar um horizonte para a execução de princípios práticos, podemos melhor compreender o que Kant pretende na IaG, ou seja, podemos pensar os princípios estabelecidos lá como voltados para o domínio prático.

Fica clara, portanto, a ligação entre a IaG e os Prol, pois neste último Kant mostra que a nossa disposição natural para a metafísica nos conduz a formular, de forma legítima, uma teoria, que nos dê a necessária esperança, para podermos atuar no campo prático, dando solidez ao nossos princípios. E malgrado, Kant no texto de 1783 esteja talvez se referindo propriamente à moral, os elementos fornecidos por Kant nos pemitem pensar uma história filosófica, tal como ele expõe na IaG.

\section{Considerações finais}

A proposta de Kant na IaG é, de acordo com o que vimos até aqui, não somente estabelecer princípios político-juridicos ou de dar esperança de uma paz entre as nações, mas antes de dar garantias ou permitir a esperança de os indivíduos se colocarem como agentes históricos (ou como ficará claro nos textos posteriores), de cumprirem os seus deveres históricos (isto é, em relação ao gênero humano) sejam eles morais ou políticos. 
Ou seja, o que Kant quer mostrar é que podemos pensar a história da humanidade "como se" ela fosse o desenvolvimento de um plano oculto da natureza para instituir uma constituição civil perfeita, na qual o homem pudesse desenvolver plenamente suas disposições naturais; e isto não com um propósito teórico, mas com um propósito prático. É na busca de garantias para tal desenvolvimento que se enquadra a concepção de história da IaG, e embora tais garantias fornecidas pela natureza só possam ser pensadas como princípios regulativos, como uma fé racional, já servem de reforço às nossas máximas de trabalhar em prol das gerações futuras dando solidez aos princípios práticos, na medida que nos incentiva a agir. De tal forma, segundo Kant, devemos assumir em nossas máximas o progresso do gênero humano rumo às constituições ideais que garantam o desenvolvimento completo e apropriado das nossas disposições como estando em curso.

A concepção de história da IaG, portanto, como uma concepção regulativa do desenvolvimento histórico serve tanto para a) orientar os indivíduos nas suas condutas, como um modelo b) como também para dar uma pespectiva consoladora do futuro, o que por si só já justifica o trabalho do filósofo ao encetar tal teoria (cf. nona proposição, A 407).

É importante acentuarmos estes dois aspectos da função da IaG citados acima: a) uma história tal como concebida na IaG pode orientar a conduta dos indivíduos na medida em que, enquanto fio condutor da história humana, indica um caminho a seguir, isto é, o estabelecimento de uma constituição perfeitamente justa, permitindo o pleno desenvolvimento das nossas disposições naturais, e que com o tempo pode vir a se constituir em um todo moral. Nesse sentido, tal modelo indica um dever para os indivíduos, o dever de trabalhar para a execução deste fim. Assim, podemos compreender com mais precisão o que Kant nos Prol quis significar quando afirmou que aquele uso imanente da idéia de teológica, ou seja, concebendo o mundo "como se" estivesse sob a direção dos desígnios de uma Providência ou Natureza, poderia contribuir para execução de princípios práticos. Pois como afirma Kant na segunda proposição, sobre o desenvolvimento pleno das disposições naturais do gênero humano 
$|126|$

O Status Epistemológico da concepção teleológica do mundo...

[...] este momento precisa ser ao menos na idéia dos homens, o objetivo de seus esforços, pois senão as disposições naturais em grande parte teriam de ser vistas como inúteis e sem finalidade - o que aboliria todos os princípios práticos - e com isso a natureza, cuja sabedoria no julgar precisa antes servir como princípio para todas as outras formações, tornar-se-ia suspeita, apenas no homens de ser um jogo infantil. (IaG: A 389).

b) Pode-se considerar a concepção de progresso histórico presente na IaG, como uma perspectiva consoladora, um incentivo ao indivíduo na tentativa de executar aqueles ideais (constituição perfeitamente justa e o desenvolvimento das disposições naturais do genêro humano), uma vez que, como Kant deixa claro na oitava proposição:

[...] a natureza humana não se mostra indiferente frente à mais longinqua época que nossa espécie deve alcançar, desde que ela possa ser esperada com segurança. Principalmente no nosso caso não deve ocorrer a indiferença, já que parece que podemos, por meio da nossa própria disposição racional, acelerar o advento de uma era tão feliz para os nossos descendentes. Graças a isso, o mais leve sinal de sua aproximação torna-se muito importante para nós. (IaG: A 404- 405).

Esta passagem de Kant (assim como as duas últimas proposições da IaG na sua integridade), é fundamental para percebermos este aspecto dos princípios ali estebelecidos: o gênero humano não se mostra indiferente quanto ao destino da espécie, e portanto, o mais leve sinal lhe serve de incentivo. Neste sentido, Kant apresenta essa história filosófica como um "quiliasmo filosófico" (IaG: 404)). Da mesma forma, na nona proposição, Kant afirma que a consideração da história segundo o já mencionado fio condutor pode servir não só para esclarecer o confuso jogo das coisas humanas ou para predizer algo na arte da política, mas sobretudo para nos abrir uma "perspectiva consoladora do futuro", pela qual podemos esperar que o nosso trabalho não será vão (IaG: A 409). 


\section{Referências}

GUYER, p. 2000. "Nature, freedom and happiness: The third proposition of Kant's.

Idea for a Universal History". In: Freedom, law and happiness. Cambridge: Cambridge University Press.

HAMM, C. 2005. "Sobre a sistematizabilidade da filosofia da história em Kant". In: Veritas; Porto Alegre: v. 50, n. 1, p. $67-88$.

LINDSTEDT, D. 1999. "Kant: Progress in Universal History as a Postulate of Pratical Reason". In. Kant-studien 90 (2), p. 129-147.

KANT, I. 1999. (RGV): A Religião dentro dos limites da simples razão. Trad. Ciro Mioranza. São Paulo: Editora Escala.

. 1980. (KrV): Crítica da razão pura. Coleção Os Pensadores. Trad.Valério Rohden e Udo Baldur Moosburger. São Paulo: Abril Cultural.

1986b. (IaG): Idéia de uma história universal de um ponto de vista cosmopolita. Org. Ricardo Ribeiro Terra. Trad. Ricardo Ribeiro Terra e Rodrigo Naves. São Paulo: Martins Fontes.

1993. (SF): O Conflito das faculdades. Trad. Artur Morão. Lisboa: Edições 70.

1986a. (Prol): Prolegômenos a toda metafísica futura. Trad. Artur Morão. Lisboa: Edições 70.

LEBRUN, G. 1986. “Uma escatologia para a moral”. In: Idéia de uma história universal de um ponto de vista cosmopolita, Org. por Ricardo Terra, Trad. Renato Janine Ribeiro. São Paulo: Brasiliense. p. 75-101.

MULHOLLAND, L. 1987. "Kant on War and Internacional Justice". In. Kant-studien 78 (3), p. 25-41.

YOVEL, Y. 1980. Kant and the philosophy of history. New Jersey, Princeton University Press. 